\title{
The Past's Affect on Development: Modernity and a Market
}

\author{
Jeffrey M. Lauer
}

\section{Introduction}

This article analyzes the redevelopment of the Gujari Bazaar - a traditional weekly market in Ahmedabad, India-by the city's most ambitious development initiative, the Sabarmati Riverfront Development Project. As neo-liberal efforts to "reclaim" (cf. Smith 1990; Chatterjee 2004) the urban centers of many cities in the global south continue, activities such as these - and the spaces they occupy - come under increasing threat. Moreover, sites of cultural heritage and historical value face interesting tensions as efforts to modernize cities move to either displace them, in order to make way for sites fitting the interests of global finance capital, or preserve them as tourist attractions, sometimes contorting them for an envisaged tourist desire.

In this paper, I argue that the Gujari Bazaar (Gujari) provides an instructive case as to the ambitions of contemporary urban development in India and the efforts of activists and spaces swept up in these ambitions work against that grain and negotiate a future for the past. It also highlights the ability of existing institutions, whether these are formal or ordinary, to adapt to new conditions. Out of this, come to light questions like: What does it mean to simultaneously consume and preserve the past? How may development ambitions intervene in that process?

While faced with an uncertain future and potential displacement, activists working to protect the market ensured its incorporation into the Sabarmati Riverfront Development Project (Sabarmati Project) by using the public interest litigation (PIL) mechanism. They leveraged its value as a site of cultural heritage, drawing out the perceived contradiction of Ahmedabadi official's simultaneous efforts to achieve World Heritage City status from UNESCO while excluding the market. While this effort was successful and allowed Gujari to 'live another day' it is crucial to investigate the implications of not only that effort, but the potential concerns with such approaches to first redeveloping and then re-presenting that past.

This article begins with a brief history of Ahmedabad's current development ambitions and the impetus that gave rise to the Sabarmati Project. Next, I discuss the Gujari's history as a market with a valid historical claim and its intersection with the Sabarmati Project and the public interest litigation that ensued. Finally, I turn to discuss what I see as some concerns for development writ-large and heritage redevelopment more specifically.

\section{Ahmedabadi Modernity and the Sabarmati Project}

Ahmedabad, located in India's western state of Gujarat, has witnessed unprecedented growth over the past several decades. In 2005, the Jawaharlal Nehru National Urban Renewal Mission (JNURM) report classified Ahmedabad as a "megacity" (Ministry of Urban Employment and Poverty Alleviation 2005). Today, the city is home to approximately 5.6 million people'. Ahmedabad in particular is often cited as one of the most prosperous and successful cities in India. Ahmedabad was founded in 1411 C.E and remained an important regional center throughout its history, but by the twentieth century grew considerably as a major center for cotton textile production. In the 1980s, a significant decline in textile manufacturing and the subsequent closure of many mills, gave rise to an image of Ahmedabad as a postindustrial city (Desai 2008). However, this image is dubious when one considers that its economy had quickly resurged by the 1990s due to considerable growth in the "... [chemical], pharmaceuticals, soaps, denim and diamond polishing" industries (Spodek 2011, 
p. 227). According to Renu Desai (2008), a "post-industrial" image is hegemonic in the narrative of global cities. She suggests, "[t]he production of this post-industrial urban image is...a central aspect of late twentieth century capitalism and the neoliberal project which mobilizes urban space for pursuing new forms of capital accumulation" (Desai 2008, p. 4).

The image of 'post-industrialization' was grafted onto Ahmedabad in order to fit the discursive space developed in the West regarding urban transformation in the 1980s and theories of globalization and modernity. This discursive reshaping imported a problem and linked Ahmedabad more firmly to concepts of Western urban theory and set it on the path of further importations of Western planning and development models. Concurrent with this re-imagination as a post-industrial city, the central government of India led major macroeconomic reforms beginning in the early 1990s. This liberalization led in part to the resurgence of Ahmedabad's economy, but also led to more aggressive and interventionist approaches to urban change-changes that sought to accommodate both an aspirant middle-class and the desires of global finance capitalism.
By the early 1990s Ahmedabad's leaders (especially Surendra Patel, who served as the Chairman of the Ahmedabad Urban Development Authority from 1995-2000 and Keshav Varma, who served as Municipal Commissioner of the Ahmedabad Municipal Corporation (AMC) from 1994-1997) had a newfound confidence, along with additional resources, to imagine a radically new urban landscape. The tool with which they pursued this image was the Ahmedabad Municipal Corporation (AMC), which became a solvent enterprise, receiving an AA credit rating in 1994. Given its ability to secure bonds at lower interest rates, the city began to initiate ambitious development projects, including the redevelopment of Chimanlal Girdharlal Road. CG Road, as it is called, is a semi-circular road located on the western side of Ahmedabad; the city on the west bank of the river is significantly more affluent and consumer-oriented [see Figure 1]. The economic development opportunity unleashed by the CG Road project led city officials to reevaluate the potential for a more ambitious development scheme along the Sabarmati River.

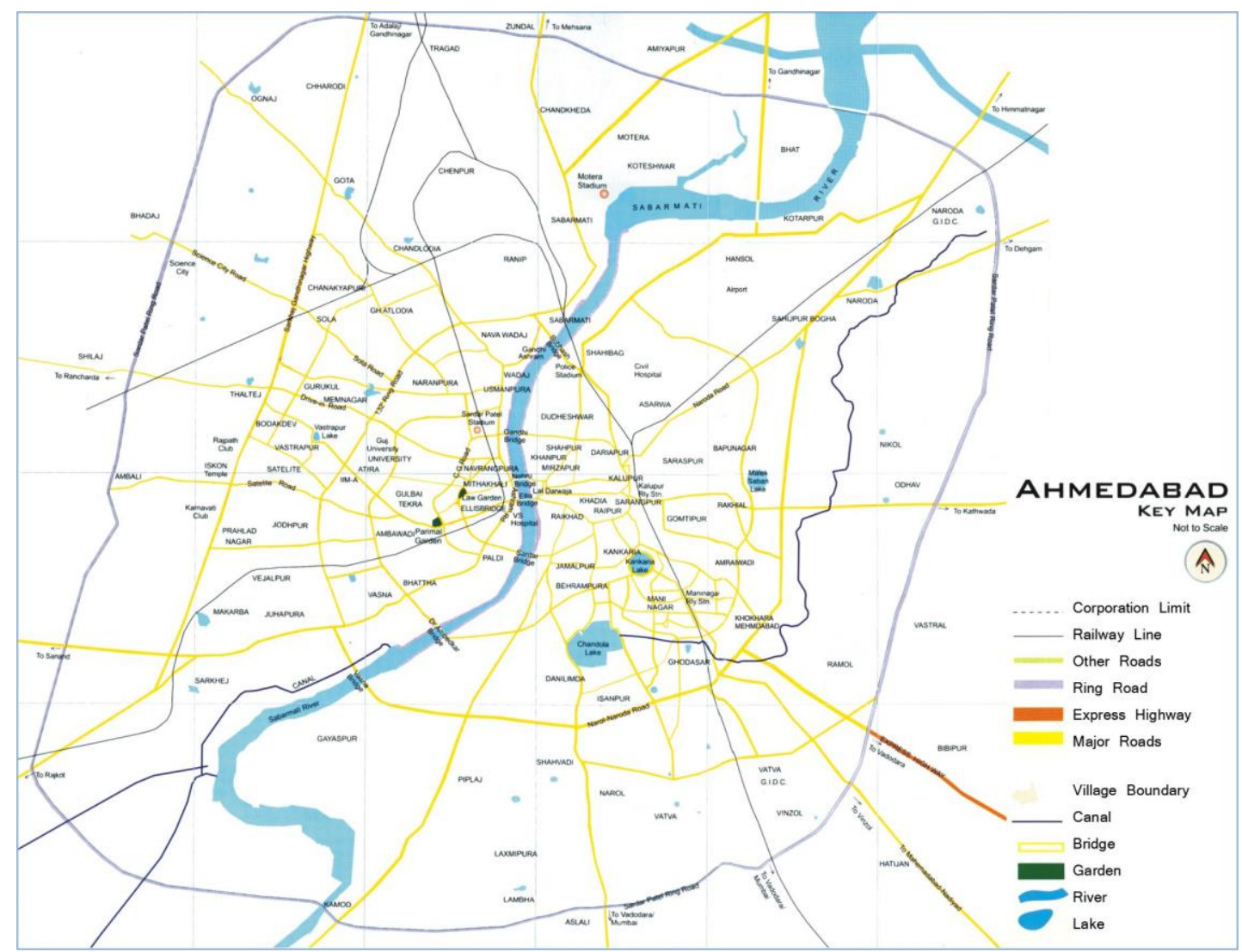

Figure 1: Map of Ahmedabad. Source: syedfawaz2002.wordpress.com 
Throughout Ahmedabad's history there have been numerous efforts to redevelop the Sabarmati River and its surrounding riverfront. Arguably the earliest proposal can be traced back to $1894^{\mathrm{ii}}$, but more recent efforts began with a proposal by French-Swiss architect Bernard Kohn in the 1960s. Kohn proposed redeveloping a portion of the riverfront between Sardar Bridge and Gandhi Bridge. Kohn's proposal “...envisaged the development of parkways, play-grounds, gardens, river-drive, boat club, civic centre, restaurants, government offices and high density housing on the banks of the river" (Shah 1981, p. 20). Many of these features would be incorporated into what would later become the Sabarmati Project, including narrowing the river for new land reclamation; moreover, the official narrative of the Sabarmati Project considers Kohn's proposal the genesis.

Although this was the first modern attempt, it was not the last. Subsequent attempts began in 1976 with the creation of the Riverfront Development Group (RFDG). When compared to Kohn's proposal, the RFDG's was conservative in vision and implementation. This conservatism was partly derived by the reality of the riverfront in the 1970s, which by then had become a site of numerous self-established settlements. This "encroachment" on municipal land made realizing the total redevelopment of the riverfront difficult, if not impossible. Thus, the RFDG only proposed to utilize existing vacant land for their redevelopment.

In addition, "[t]he group rejected the commercialization of land because they felt there was already excessive commercialization on the riverfront" (Desai 2008, p. 137).
Ultimately, similar to Kohn's proposal, the RFDG's plan was disregarded due to financial and other reasons.

Emerging from this context in the late 1990s, the Environmental Planning Collaborative published The Proposal for the Sabarmati Riverfront Development Project Ahmedabadii in May 1998. The proposal called for the reclamation of 162.8 hectares of land along both banks of the Sabarmati River. The proposed land uses included: roads, gardens, promenades, relocation sites, informal markets, commercial and residential areas and public facilities [see Figure 2]. The design included wide two-tier public promenades that would afford beautiful vantage points of a perennially filled river. This inner-urban riverfront redevelopment initiative was comprehensive in scope. It aimed to redevelop twelve-kilometers of the Sabarmati River along both east and west banks. Its mission was to transform Sabarmati's "marginal" and "leftover" banks into? Within this massive scope, the Sabarmati Project included portions of Ahmedabad's "Old City" that dates back to the early 15 th Century.

When conceived in 1998, the Sabarmati Project was contemplated to function as a development and infrastructure corridor at the center of the city. This was to be achieved by "reclaiming" (or creating through landfill) additional real estate for public facilities, social activities and commercial land uses. "It [the SRFDP] is an ambitious multidimensional environmental improvement, social uplift and urban rejuvenation project" (Patel 2011a).

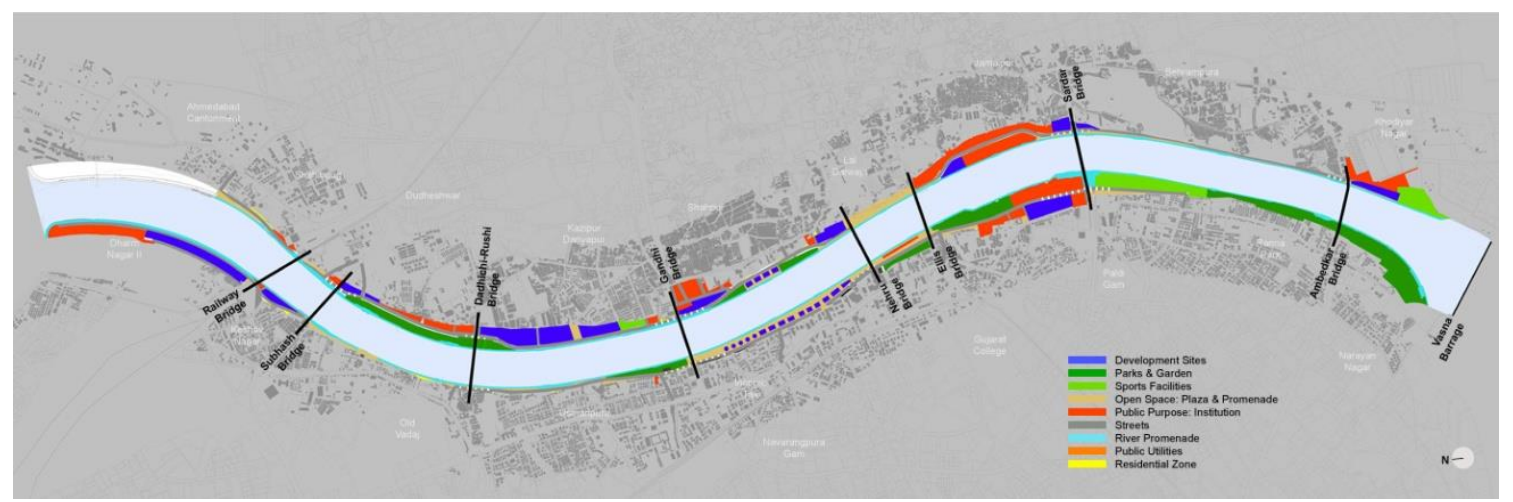

Figure 2: Master Plan of the Sabarmati Riverfront Development Project. Source: HCP Pvt. Ltd. 
Its goals are clearly expressed by Gujarat's then Chief Minister Narendra Modi (now Prime Minister of India):

The Sabarmati Riverfront Development Project will transform Ahmedabad's historic but neglected riverfront into a vibrant and vital focus for the city. The project consists of several linked initiatives aimed at addressing the many environmental and social problems of the riverfront ${ }^{\mathrm{iv}}$

The proposed vision, complete with roads, gardens and open spaces, promenades, multiuse commercial areas, sports and convention centers, and markets was unprecedented. Furthermore, the ambition to pursue a megaproject of this scale was unprecedented in not only Ahmedabad or Gujarat, but also arguably India in general.

The proposed aesthetic was sleek, high modernist (read Brutalism) and uniform [See Figure 3]. In this vision, Ahmedabad's riverfront becomes a new spine of postcolonial modernity; a new spatial archetype that intends to remake other localities in its image. In 2011, a special issue of Metropolis magazine appeared with the title "Indian Cities: Managing Urban Growth", in which Bimal Patel, project architect, wrote an article entitled Riverfront Renewal. In this article, Patel stresses, "[t]he Sabarmati Riverfront Project by the Ahmedabad Municipal Corporation is a good example of changing the character of a city from the centre [sic] outwards in a way that is environmentally and socially responsible" (Patel 2011b, p. 104).

The above sections have highlighted the redevelopment vision currently at work in Ahmedabad. This vision is spurred by economic objectives to compete and to stay relevant in the story of globalization, but it's vision is supplied by local architects either trained in the West, like Bimal Patel of HCP Pvt. Ltd., and/or by a process of collecting desired images and information from the transnational flow (Appadurai 1996). Similarly, as Asher Ghertner has argued in his framework of "aesthetic governmentality" (Ghertner 2011, pg. 289): [the] ....aesthetic approach allows government to overcome the (political and bureaucratic) difficulty of translating messy "reality out there" (e.g., population densities, land-use designations, territorial area, settlement history, etc.) into a numeric or cartographic legibility. Thus, instead of having to inscribe the population and its complex relation with things into standardized, abstractable forms that can be aggregated, compiled, assorted, and then calculated, this "aesthetic governmentality", or rule by aesthetics, works to ascribe an aesthetic sense of what ought to be improved and what ends achieved. Government legibility is achieved today, then, not by (statistically) simplifying territory into easily intelligible representations, but rather the reverse: it takes an idealized vision of the world-class city gleaned from refracted images and circulating models of other world-class cities (a little Singapore here, a little London there) and asks if existing territorial arrangements conform to this vision.

Ghertner's argument is consistent with what Ananya Roy (2008) has called "models-incirculation". It is within this context that projects like the Sabarmati Project were conceived and given shape. Furthermore, this shape is one that not only bares the consequence of redevelopment, or even renewal, but is also wrapped in a discourse that marginalizes spaces and activities, like Gujari, and virtually prohibits them from joining this vision on their own terms. However, it was Gujari's eventual inclusion in the Sabarmati Project, despite the presence of a project intent on nothing less than remaking modern Ahmedabad, that made it all the more significant. 


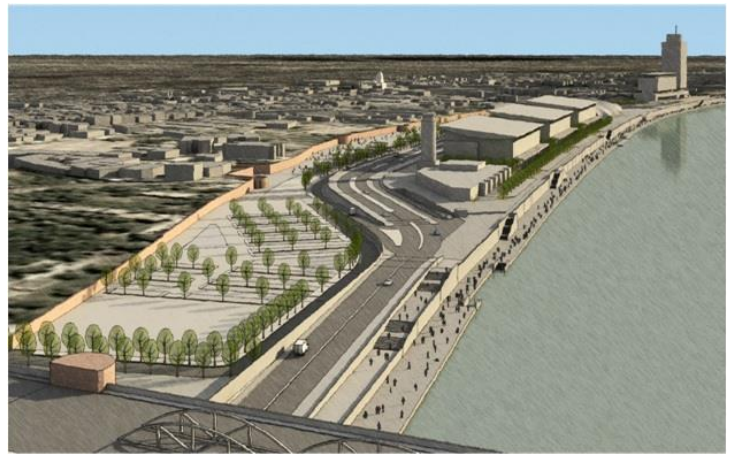

Figure 3: Rendering of the convention centre along the Sabarmati River. Source: HCP Pvt. Ltd.

By the time the above article in Metropolis magazine was published, construction along the river had fallen into controversy. The high number of dense pre-existing activities along the riverfront like self-established settlements began organizing political movements against displacement (Desai 2008). Additional activities, like "informal" markets fell within the same lens of controversy for the Sabarmati Project ${ }^{\mathrm{v}}$. Early on in its construction, many at the time understood the self-established settlements to be threatened with displacement because of the Sabarmati Project. By the time I returned to Ahmedabad to resume fieldwork in 2013 for my graduate thesis, nearly all self-established settlements had been displaced, some of which were relocated as a result, some to resettlement communities, largely on the outskirts of town. These displacements produced an uncertain and insecure atmosphere for many other activities that were still operating along the river and in the perceived path of development.

One such activity was Gujari-a weekly traditional market. As time went on and construction activity drew closer, Gujari was forced to accommodate construction vehicles and materials, as well as the physical retaining wall designed for reclamation purposes. As a result the sense of insecurity and urgency increased exponentially.

\section{The Gujari Bazaar and Public Interest Litigation}

The word gujari, may be translated from Gujarati as departed, dead, or passed ${ }^{\mathrm{vi}}$, but refers in this context to antiques, things that have past away or gone out of style. The word bazaar means market; it is a term broadly used across South, East and Southeast Asia. Until early 2014, Gujari occurred every Sunday (also known as Ravivari or Sunday Market) on a small piece of open land along the Sabarmati River, adjacent to Ellis Bridge and around the Mahalaxmi Mandir (temple).

In the attempt to acquaint a stranger with Gujari, here is a random list of merchandize one may find: books, magazines, steel containers of all sizes, pots and pans, cans of paint, charpies (beds), antique coins, forgotten electronics, tools, laries (hand carts), portable DVD players, bird cages, CDs, toys, sports equipment, exercise bicycles, new and used furniture, goats, chickens, rabbits, and mirrors [See Figure 4]. The form is typical of what one might find in an improvised or ad hoc gathering of street vendors in cities across South Asia. Gujari is largely self-organized and managed by an intricate system of membership and licensure by a representative internal group of traders called the Ahmedabad Gujari Association (AGA). What is unique about Gujari, even from other daily or weekly markets in Ahmedabad, is a significant historical claim.

There is no published history of Gujari ${ }^{\text {vii }}$, although there are elaborate oral narratives that I received from the president of the AGA. According to these narratives, the market originated by a royal decree in 1414 C.E. issued by Sultan Ahmed Shah-founder of the city of Ahmedabad ${ }^{\text {viii. }}$. Due to this, many government agencies, brochures, newspapers and academic articles claim this market is over 600-years old, carrying on a tradition from the early 15th century. It is a part of the identity of Ahmedabad.

According to these narratives the market originally took place on Fridays, instead of Sundays, in a previous location for 527 years until 1941, when communal riots forced it to close temporarily.

This event marks a major rupture in the market's history. When the weekly market reopened after two months, vendors, whether the same or not, could no longer operate. The narrative is fuzzy as to why the market could not resume operations at its previous location. 


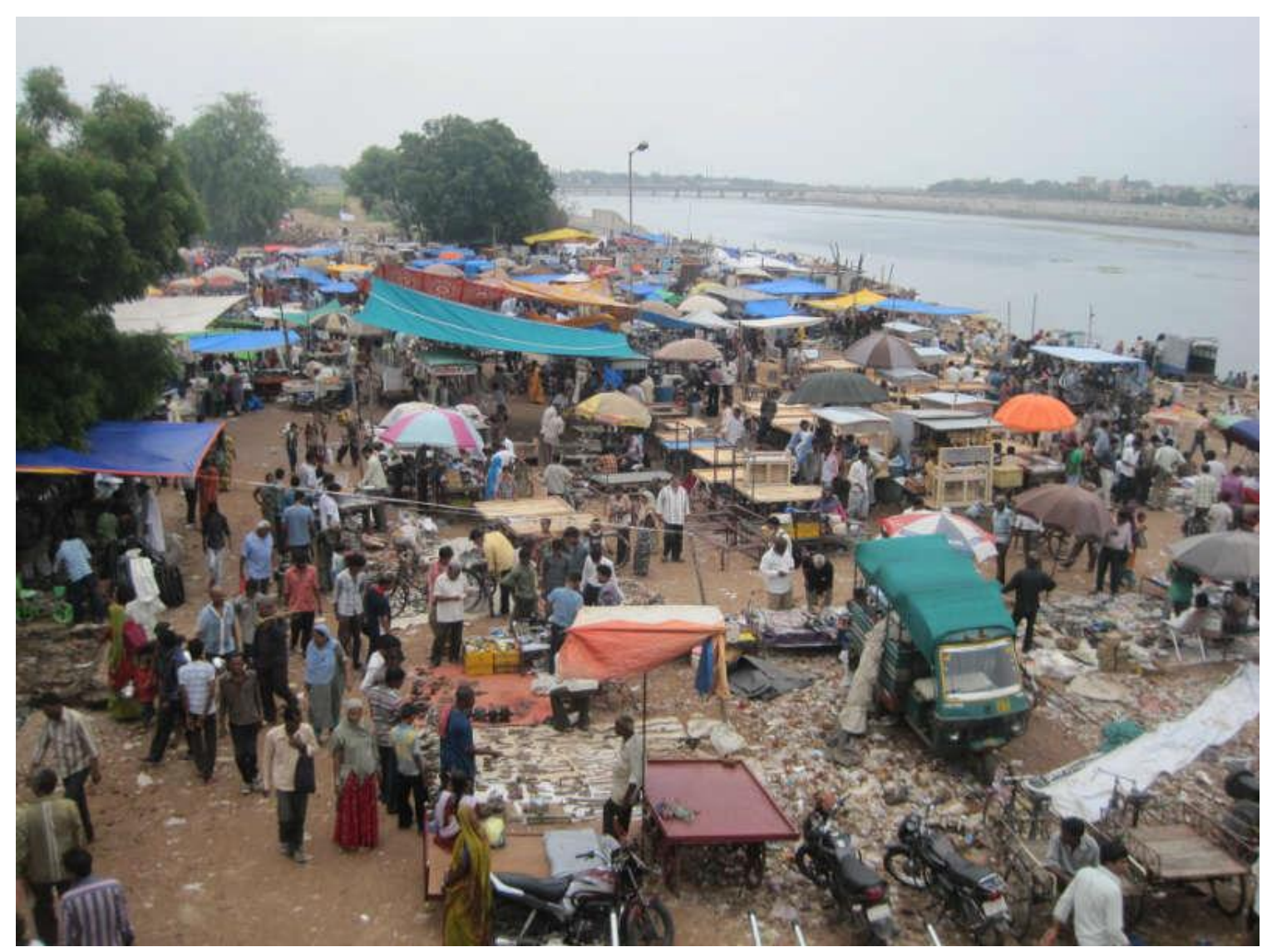

Figure 4: Photograph of the Gujari Market taken from Ellis Bridge. Credit: Tarun Gagdekar, 2013

Vendors briefly relocated around Sidi Saiyyed Masjid, but soon found a new home at its location along the Sabarmati River.

The Sabarmati River has long been a site of public use. Perhaps the most famous public assembly involving the Sabarmati River took place in approximately 1930, when Mahatma Ghandi addressed a large crowd from a platform in the riverbed. Additionally, it has been popular as a site of dhobiwalas, as well as religious ritual. Since the 1960s the development pattern of Ahmedabad was generally oriented away from the river and outwards, with most new development occurring on the western side of the city. As a result, the banks of the river became a site for self-established settlements and eventually activities like Gujari.

Any development project along the riverfront was bound to encounter the question of what to do with these existing activities. The earlier RFDG proposal along the riverfront proposed a narrow and conservative scope, something akin to Geddes' "conservative surgery", due to the complexity and density of such activities. However, the Sabarmati Project's scope encompassed nearly all existing activities. The first mention of Gujari's redevelopment in the original 1998 plan for the Sabarmati Project, and the subsequent update in 2004, is in the proposal brief in a section titled "Provision for informal markets". That section of the report states the following:

...informal markets (Gujari and Phool Bazaar), which are of economic importance to the poor, lack accessibility, parking space, water supply, public toilets, and ancillary facilities and take place in an unorganized manner...The SRFD Project will strengthen, upgrade and enlarge the existing two markets...thereby benefiting the vendors and creating additional employment opportunities. All the informal markets will be developed on 
elevated land and have a planned layout with semi-permanent stalls, plinths and facilities such as parking, water supply and public toilets. Thus the vending activities can occur all year round...the provision of facilities will also mean that high-income people of the city would frequent these markets (Environmental Planning Collaborative 1998, p. 5).

Two issues arise from this passage. First, all of the matter-of-factly stated "deficiencies" above are spatial or design-oriented in nature. Architects and planners for the Sabarmati Project privileged the aesthetic or physical (read tangible) aspects of the market over people and their social context, paying attention instead to what they were concerned about: health and design. Furthermore, these "deficiencies" are couched, not uncommonly, in a discourse of public health and sanitation. The bazaar has historically been a site of concern for colonial administrators. While it is formally a site of economic transaction, for local people it is "...geared to the production of social life" (Charakarbary 2002, p. 73). Thus, it becomes the gathering place of "crowds". As Dipesh Charkarbarty (2002) has argued, colonial administrators were worried about indigenous gatherings like bazaars where rumors and plots could be discussed and epidemics spread. Perhaps given this legacy, it is not surprising that the discourse surrounding the redevelopment of Gujari would veil itself in the language of public health and sanitation.

Such colonial representations serve to essentialize spaces like Gujari and deny them and their practitioners' coevalness with the modern city (Fabian 1989). Second, the passage remarks that one of the envisaged benefits of the market's incorporation is that "...high-income people of the city would frequent these markets" (Environmental Planning Collaborative 1998, pg. 5). Such pronouncements ignore the diverse clientele which does patron the market or the common tradition of mothers and mothers-in-law bringing brides to Gujari on the eve of or shortly after their weddings to assemble a new set of pots, pans and kitchen supplies. Rather it paints a picture of a market as one of the poor, for the poor.
Further on, the report does make casual acknowledgement of Gujari's history, "[t]he traditional market has been a feature of the city since a very long time" (Environmental Planning Collaborative 1998, p. 34). Nevertheless, the market is categorically defined by the heading "Informal Markets" and referred to as such numerous times. The reason this is significant is that many of the displaced self-established settlements were painted with the same "informal" brush and conjures of the impoverished images as discussed above that help justify redevelopment.

Despite being explicitly referenced in the original report (and the 2004 update) and provided land in the Sabarmati Project's conceptual plans, evictions along the riverfront led to a sense of vulnerability and distrust between the AMC and the AGA. Furthermore, this sense was only amplified by problematic governance strategies, like what Darshini Mahadevia (2011) has called "deliberate policy confusion". In this, policy "swing[s] in the direction..." of public or economic pressure which dismantles a cohesive and documented urban vision due to fragmented and ad hoc implementation. Furthermore, Desai (2012) has diagnosed what she calls "flexible governing", a process whereby the implementation of specific projects can pursue a path of least public resistance until such can be domesticated and overcome. In this vein, the 1998 and 2004 reports are consistently vague regarding the market's redevelopment. Neither provides details about whether the AMC will simply provide a communal space for market activity open to all or if specific vendors (i.e., those with active memberships) would be exclusive participants.

In an effort to counter such uncertainty, in April 2011, Gujari's leadership recruited students from the Indian Institute of Management-Ahmedabad and the National Institute of Design to help redesign the market and rethink and imagine how it might engage with the Sabarmati Project. By then, HCP Design, Planning and Management Pvt. Ltd. (HCP) - the planning and design firm behind the Sabarmati Project—had already conducted a highly publicized exhibition of professional designs for the Sabarmati 
Project, including the promenades and Gujari [See Figure 5]. These images go far beyond any marketing material produced for the Sabarmati Project at that time in the development process. They are highly detailed computer-rendered images and allow a would-be-vendor to imagine themselves within the space. Furthermore, because the exhibition was held off-site on the campus of Centre for Environment, Planning and Technology (CEPT) University, not easily accessible to many vendors (Mathur 2012) and that the images have a certain resolute quality about them, it is fair to suggest that this exhibition was not intended to collect feedback from vendors and meant more as a showcase of the final designs. This lack of vendor input is all the more evident in the official survey of Gujari that HCP conducted in early-2011. In this survey Gujari was arbitrarily divided into four distinct zones, classified as A through D, without any rationale for this conceptual distinction, other than research efficiency. What is quickly apparent is that ordinary people, especially vendors, were not consulted. No interviews were taken and with the exception of a few photographs, people are virtually absent. The lens through which this survey was conducted was purely aesthetic and physical.

Upon receiving a Right to Information (RTI) request, market officials, and other social activists, discovered that despite renderings showing Gujari's inclusion there was:

...no formal plan to rehabilitate the market, nor had it announced a request for proposal (RFP) for the design of the bazaar. There had been no official communication about the status of the bazaar with the traders' association [the AGA]. However, space for their operation was decreasing everyday owing to construction work for the riverfront project (Mathur 2012, p. 70).

As a result, Mr. Mathur vs. The State of Gujarat was filed as PIL ${ }^{\text {ix }}$ to "[protect] the fundamental rights of vendors of the 600 years old Historical [sic] bazaar ..." (High Court of Gujarat 2011, p. 1). The substance of the petition suggests that concerns of social justice undergirded the litigation. It references confusion between the AGA and AMC led by conflicting articles in local newspapers and a discovery that according to the current (2011) redevelopment proposal, Gujari would only be allotted 615 vendor spaces. Given that preliminary surveys indicated a number much higher and the fact that the AGA had a registered list of 1,200 vendors, it was clear that the contemplated space would produce numerous exclusions and disenfranchises a significant number of the market's registered vendors. While the PIL sought to protect the economic livelihoods of vendors, the main argument put forth to secure its protection was its value as a site of local cultural heritage.

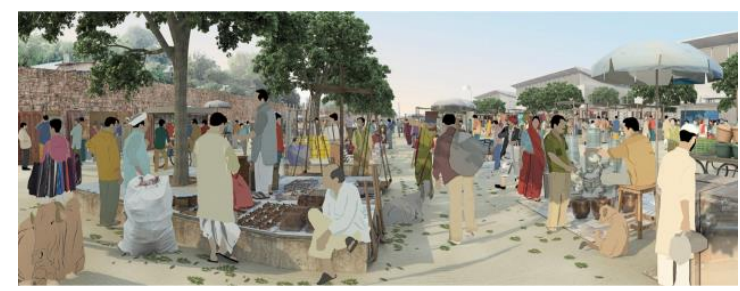

Figure 5: Rendering of the Proposed Gujari Bazaar. Source: HCP Pvt. Ltd.

Around the time this PIL was filed, the City of Ahmedabad, including the AMC and AUDA applied for World Heritage City status from UNESCO by leveraging its numerous historical and cultural assets. By doing this, officials sought to simultaneously distinguish Ahmedabad as a city that welcomed global investment and world-class development, but did not eschew its local history, but rather embraced and protected it. Although this market's history is widely acknowledged in the public's imagination (i.e., publications, $\mathrm{TV}$, newspapers), Gujari was not included with this submission. Upon discovering this, Navdeep Mathur, a professor at the wellknown Indian Institute of ManagementAhmedabad, who initially filed the PIL, and other advocates worked to designate it as a heritage site or, at the very least, seek wider transnational acknowledgement of its history. In late April 2011, a group of social activist and academics submitted a letter to the UNESCO Office in New Delhi, India. The letter identified three historical sites or communities throughout Ahmedabad and highlights the fact that these sites are missing 
from the city's bid for World Heritage City status. The letter describes the market as, "...a 596 year old open informal market that continues to this day run by the community organization of traders that comprises both Hindus and Muslims" (Chhara, D. et al. 2010). In response, the UNESCO Office in New Delhi submitted a letter to Ahmedabad's Municipal Commissioner urging the city to consider these sites in their development schemes (Torrandes, J. 2010).

Although concerns of social and economic justice are central to the motivations of the PIL, impetus for the market's protection is couched in claims of its cultural value through the discourse of heritage, as expressed in the passages above. Certainly, what makes Gujari unique when compared to other "informal" markets within Ahmedabad (i.e., consider the Phool Bazaar which did not receive equal attention) is its historical claim. Amid the fervor of the UNESCO bid, the discourse of heritage became a strategically significant entry point to national and transnational forms of cultural credibility and validation, but it also situated the market firmly within a local context by picking up on a continuous and un-ruptured notion of history that linked it with the founding of Ahmedabad itself. The PIL re-presented the market's history as one continuous practice from the 15 th century.

As Lynn Meskell (2015) argues, heritage is arguably, "...a supplement to history...it completes and elaborates upon what is missing from the past in the present, serving as an accretion and a substitution" (Meskell 2015, pg. 2). However, she is quick to caution, "[t]here is no unmediated past... [o]urn negotiations and endless iterations reveal that the past is always already a representation of a representation" (ibid). The notion that heritage and traditions are representations (cf. Handler and Linnekin 1984) and therefore malleable to suit present circumstances and political interests (cf. Hobsbawm and Ranger 1983) is nothing new. As Meskell says, heritage is quite "slippery" (Meskell 2015, pg. 2). By no means do I suggest that Gujari's tradition or history was fabricated to suit its political interest of inclusion. Rather, I argue that in this case heritage was politically deployed. Given the context of Ahmedabad's ambition to be designated as a World Heritage City, Gujari's heritage played a significant role and activists saw it as a supplement to Ahmedabad's history; one that elaborates and provides a more colorful and richer narration on an event of history (i.e., the city's founding). In doing so, the discourse of heritage was an attempt to reach out for established transnational avenues of cultural validity. It argued that Gujari was a historical tradition not only worth preserving but one actually consistent with the Sabarmati Project's vision. Gujari thus found a way to continue beyond its 600year old history, but by transforming it to fit within the new order and the built environment.

Some scholars (Holston 1989; Scott 1998; Scott 1985) have argued that aversion to or evasion from the state is what works to secure the continued existence of "informal" spaces like Gujari and self-established settlements. Using James Scott's concept of "legibility"which argues that the state works to make local social-space legible, even to a stranger or outsider, by renaming and reorderingthese scholars suggest that by being ambiguous or unable to be read (i.e., illegible), serves as a survival strategy. Indeed what is most unique in this respect to the journey of Gujari is that its "survival", which, in this instance, meant inclusion into the project, was sought not by remaining adverse or increasing its illegibility, but by closer proximity to state apparatuses like the private planning firm overseeing the project, the AMC and the Gujarat Supreme Court.

By late 2011, the PIL was settled and a memorandum of understand (MoU) was signed between the AGA and the AMC (2011). This MoU definitively assigned space within the Sabarmati Project for Gujari, with accommodations for 1,200 vendors. In the interim, the market was allowed to continue operating at its previous location until all improvements were completed. In early 2014 , the market was officially shifted to its new location. Gujari's new location is consistent with the renderings shown above, the schematic design included with the MoU and descriptions of the new design included in the original 1998 and 2004 proposals. It is 
designed with raised platforms, pay-to-use toilet facilities and offices for the AGA.

The Gujari's new location is nestled within the primary nexus of tourist activity on the entire Sabarmati Project. Furthermore, its historical presentation, but labeling as a "Riverfront Market", with the subtle implication of an ancient market, give cues of Gujari as an intended spectacle of "authentic" Ahmedbadi culture. It is paradoxically framed within a modernist aesthetic, all the while 'out of the past'. While the new design otherwise conforms with the middle-class images of desire represented in the renderings, Gujari's new location is sandwiched between the new exhibition center and the historic fort wall built in the 16th century [See Figure 6]. This node of the Sabarmati Project is contemplated to have one of the highest concentrations of activity, and is geared towards domestic and international tourists. However, the design for the Gujari's new space can only be described as modern (perhaps Le Corbusian). The design is consistent with numerous other facilities and locations within the Sabarmati Project, although this is the only location exclusively dedicated to market activities.

However, Gujari is not the sole user of the space. During an interview with the Sabarmati Project's lead designer, Nikki Shah (as of 2013), he stressed that providing space for Gujari quickly encountered a problem, "Gujari only takes place on Sundays. So we had to answer: how will the space be used the other six days of the week?" According to the designers, the most utilitarian solution was to share the space among several activities, including the Phool Bazaar or flower market that currently operates just south of Gujari's location. Furthermore, the ideal is to permit additional activities in the space. This elaborate new schedule, with oscillating uses on different days during the week, is not only a Western approach to the utilization of space, but represents a thematic reprogramming. The theme and identification of the space changes dramatically day to day and is no longer exclusive.

As Figure 6 shows, Gujari is shown at the top of the image between the fort wall, as discussed above, and the location of a contemplated convention center and exhibition hall. Flanking the market on both sides are parking lots designed to accommodate automobile traffic attending Gujari or the approximate riverfront activities. The main thoroughfare for the Sabarmati Project is the riverfront road, which separates Gujari and the future convention center. This spatial context has effectively defined Gujari on all four sides and will surely prohibit spatial expansion as Gujari continues into the future. Before, Gujari was virtually unburdened by spatial impediments. As it needed to grow and morph, it did, sometimes expanding into bed of the Sabarmati River when dry. But the new context, which I have termed reframing, has fixed Gujari in place, effectively frozen it in time and place. Doing so, will not allow Gujari to development on its own terms

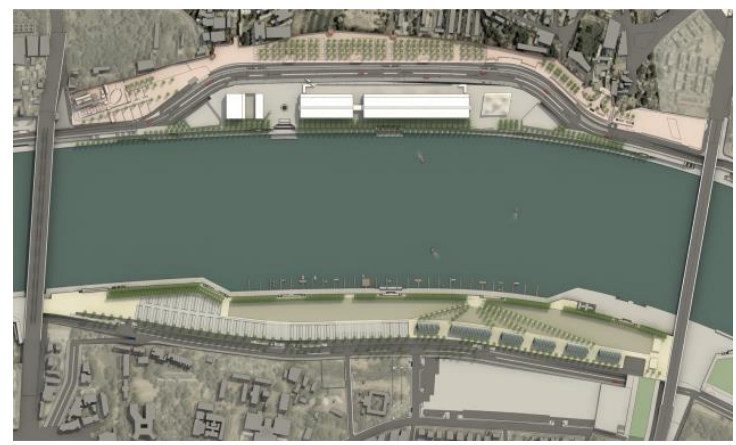

Figure 6: Rendering of Gujari as shown from above. The market is located at the top of this image and directly below that, but still on the east (north in this image) side of the river is the location of the proposed convention center. Source: HCP Pvt. Ltd.

\section{Conclusions}

This paper explores the complex and often obfuscated intersection of simultaneously preserving and consuming the past, as well as the continuity and change of historical institutions and spaces. Ahmedabad's contemporary development vision is one fueled by a middle-class desire to "reclaim" the city (Smith 1990; Chatterjee 2004); to seek revenge for territory perceived lost. The Sabarmati Project is in many respects the jewel in the crown of Ahmedabad's new urban modernity, but its vision for the future 
quickly came in conflict with Gujari and its historical tradition.

While there are some indications, in the original project proposal from 1998, that suggests an original intent to include the market, the reality of construction and political protest occurring along the riverfront squeezed the market's operations and led to confusion and distrust (further echoing a theme of this special issue that emphasizes the disconnect between planner's intent and the reality on the ground). Eventually, this led to the requested intervention of local activists who worked to guarantee the market's inclusion. However, while public exhibitions and well-produced renderings attempted to illustrate a future of the market within the Sabarmati Project, confusion and a lack of communication and input between the AMC and the AGA reached a fever pitch in litigation.

Interestingly, rather than establish a strict legal claim for the market's inclusion or an appeal to social justice (i.e., "right to the city") (cf. Harvey 1973), activists working for Gujari achieved inclusion by an alternative path. Gujari and its advocates did not argue that it is a site for middle-class consumption, thus attempting to conform to the Sabarmati Project's images of desire; nor did they argue that it was strictly a site for conservation. Rather, they sidestepped this dichotomy (or displaced it) and used the discourse of heritage in an attempt to reach out for established transnational avenues of cultural validity.
It argued that Gujari was a historical tradition that supplemented (perhaps even complemented) the narrative of Ahmedabad that elites and planners wanted to glorify in their attempt to achieve World Heritage City status from UNESCO. Gujari thus found a way to continue beyond its 600-year old history, but by transforming it to fit within the new order and the built environment of the Sabarmati Project.

After gaining inclusion, however, Gujari's new space is characterized by what I call a thematic reprogramming and a contextual reframing. The new market has been reprogrammed per a utilitarian Western philosophy that attempts to maximize value, thus transforming it into a market venue open to various activities. Gujari is no longer associated with an exclusive possession of space, but one among many. Additionally, the spatial context has framed Gujari within not only a new nexus of domestic and international tourist consumption, but has also frozen Gujari in time and place and prohibited it from expanding and developing on its own terms. The proximity of this market venue adjacent to the exhibition hall and convention center and its labeling as a "Riverfront Market" (which subsumes Gujari's historical identity) indicates the intent of Gujari to facilitate the needs of the Sabarmati Project to serve as a site of middle-class consumption; consumption of both a past and future Ahmedabad.

\section{REFERENCES}

Appadurai, A. (1996). Modernity at Large: Cultural Dimensions of Globalization. Minneapolis, MN: University of Minnesota Press.

Chakrabarty, D. (2002). Habitations of Modernity: Essays in the Wake of Subaltern Studies. Chicago, IL: The University of Chicago Press.

Chatterjee, P. (2004). The Politics Of The Governed: Reflections On Popular Politics In Most Of The World. New York: Columbia University Press.

Chhara, D., Ahmed, N., Bhati, M., Jadav, B., Mahadevia, D., Kachru, T., Mathur, N. (2010, April 28). [Letter to Mr. Armoogum Parsuraman]. Ahmedabad, Gujarat.

Chhipa, N. I. (2010, November 29). Seeking Partnership for Community Heritage Conservation, Historic Market [Letter to Mr. Manel Ripoll i Estera]. Ahmedabad, Gujarat. 
Desi, R. B. (2009). The Globalizing City in the Time of Hindutva: The Politics of Urban Development and Citizenship in Ahmedabad, India (Doctoral dissertation, University of California, Berkeley, 2008) (pp. 1-349). Ann Arbor, MI: ProQuest LLC.

Desai, R. (2012, January 14). Governing the Urban Poor: Riverfront Development, Slum Resettlement, and the Politics of Inclusion in Ahmedabad. Economic and Political Weekly, 47(2), 49-56.

Environmental Planning Collaborative. (1998). Proposal for Sabarmati Riverfront Development: Ahmedabad (India, Sabarmati Riverfront Development Corporation Limited). Ahmedabad, Gujarat: Environmental Planning Collaborative.

Fabian, J. (1983). Time and the Other: How Anthropology Makes Its Object. New York, NY: Columbia University Press.

Ghertner, D. A. (2011). Rule by Aesthetics: World-Class City Making in Delhi. In A. Roy \& A. Ong (Eds.), Worlding Cities: Asian Experiments and the Art of Being Global (pp. 279-306). West Sussex: Blackwell Publishing.

Gillion, K. L. (1968). Ahmedabad: A Study in Indian Urban History. Berkeley and Los Angeles, CA: University of California Press.

Handler, R. and Linnekin, J. (1984). Tradition, Genuine or Spurious. Journal of American Folklore, 97(385), 274-290

Harvey, D. (1973). Social Justice and the City. Oxford: Basil Blackwell.

Holston, J. (1989). The Modernist City: An Anthropological Critique of Brasila. Chicago: University of Chicago Press.

Hobsbawm, E. and Ranger, T. (eds.) (1983). The Invention of Tradition. Cambridge: Cambridge University Press.

Mahadevia, D. (2011, July). Branded or Renewed? Policies, Politics, and Processes of Urban Development in the Reform Era. Economic and Political Weekly, 46(31), 56-64.

Mathur, N. (2012, December). On the Sabarmati Riverfront: Urban Planning as Totalitarian Governance in Ahmedabad. Economic and Political Weekly, 47(47 \& 48), 64-75.

Meskell, L. (ed.) (2015). Global Heritage: A Reader. West Sussex: Wiley Blackwell.

Mr. Mathur vs. The State of Gujarat (High Court of Gujarat January, 2012).

Patel, B. (2011). Riverfront Redevelopment. Metropolis, 95-105.

Scott, J. (1998). Seeing Like a State: How certain schemes to improve the human condition have failed. New Haven: Yale University Press.

Scott, J. (1985). Weapons of the Weak: Everyday forms of peasant resistance. New Haven: Yale University Press.

Shah, K. (1981, October). River Front Development Scheme; Will it remain a blueprint? Amdavadma, (11), 19-34.

Smith, N. (1990). Uneven Development: Nature, Capital and the Production of Space. Oxford: Basil Blackwell Publisher.

Spodek, H. (2011). Ahmedabad: Shock City of Twentieth-Century India. Bloomington: Indiana University Press.

Torrandes, J. (2010, December 1). [Letter to Mr. Nafis Ahmed Ishak Allahwala Chhipa]. Barcelona, Spain. 


\footnotetext{
${ }^{\mathrm{i}}$ According to the 2011 Indian Census.

${ }^{\text {ii }}$ A small group of Ahmedabadi industrialists formed the Gujarat Navigation Company that aimed to dredge the Sabarmati River in order to make it navigable for commercial shipping (Gillion 1968). Although this proposal was seen as too "visionary" and quickly abandoned, it is significant to note that it ignored cultural or recreational opportunities the river and its banks may have provided and suggests a utilitarian view of the river.

iii This was not the first proposal to redevelop the Sabarmati Riverfront. Perhaps the earliest can be traced back to the late 19th century, which proposed to dredge the river for commercial vessels. The first modern proposal to redevelopment the riverfront is often traced to French architect Bernard Cohn.

${ }^{\text {iv }}$ As accessed on the project's website: http://www.sabarmatiriverfront.com/1/about-us

"According to the "official" survey (conducted by a Mumbai based NGO), by 2000 at least 14,550 (Mathur 2012, p. 172) families resided on the Sabarmati River; however, an unofficial survey estimated a number closer to 40,000 (Mathur 2012, p. 65). The initial plan from 1998 determined there were only 4,400 households in the Project Affected Area (the "PAA") and it proposed rehabilitating 6,000 "slum dwellers" on the riverfront (cf. EPC 1998, p. 43-45), however, as time passed and substantive construction began it was decided to relocate them (Desai 2008; 2012). By 2010, heavy construction had increased in scope and it became necessary to clear the riverfront of self-established settlements within the PAA. Displacements began in earnest starting in mid-2011, although some relocation had occurred as early as 2009 (Desai 2011, p. 49). For these residents, relocation and rehabilitation schemes were prepared with eight separate resettlement sites dispersed across the city. According to an interview I conducted with Ahmedabad's Municipal Commissioner, Guruprasad Mohapatra, out of 13,000 applications for rehabilitation only 12,000 were approved. Of these, 9,000 were actually resettled. The remaining 3,000 were deemed ineligible or were unable to furnish the necessary documents or initial payments (see Desai 2008 for further discussion on slum resettlement). Resettlement and Rehabilitation due to the SRFDP was elaborate. According to this rehabilitation scheme, an approved family had to furnish 5,000 rupees in order to secure and move into a home. After this, each family was required to pay 60,000 rupees in monthly installments.

"For instance the Gujarati word gujar may be translated as "dead."

${ }^{\text {vii }}$ While it is not published, the longest serving market president-M. Ishak Allahwalla - has hand-written a roughly 600-page history of the Gujari Bazaar in Gujarati. His son Nafis Chippa, the current president of the AGA, currently holds this history.

viii Interview with Nafis Chippa, March 2013

${ }^{\text {ix }} \mathrm{PIL}$ is a judicial process that provides recourse to historically oppressed and underrepresented communities. In India, anyone can file a PIL on behalf of another as long as it is in the public interest. ${ }^{\mathrm{x}}$ Interview with Nikki Shah at HCP's office, May, 2013.
} 